\title{
Measuring job stress in transportation workers: psychometric properties, convergent validity and reliability of the ERI and JCQ among professional drivers
}

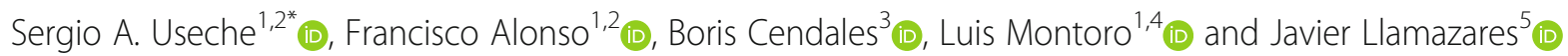

\begin{abstract}
Background: The accumulated evidence has shown how professional drivers are, in psychosocial terms, among the most vulnerable workforces, and how their crashes (some of them preceded by stressful working conditions) constitute both an occupational and public health concern. However, there is a clear lack of validated tools for measuring stress and other key hazardous issues affecting transport workers, and most of the existing ones, frequently generic, do not fully consider the specific features that properly describe the work environment of professional driving. This study assessed the psychometric properties, convergent validity and consistency of two measures used for researching occupational stress among professional drivers: the Siegrist's ERI (Effort-Reward Imbalance Inventory) and Karasek's JCQ (Job Content Questionnaire).

Methods: We examined the data collected from 726 Spanish professional drivers. Analyses were performed using Structural Equation Models, thus obtaining basic psychometric properties of both measures and an optimized structure for the instruments, in addition to testing their convergent validity.

Results: The results suggest that the abbreviated versions of ERI (10 items) and JCQ (20 items) have clear dimensional structures, high factorial weights, internal consistency and an improved fit to the task's dynamics and hazards, commonly faced by of professional drivers; a short set of items with low psychometrical adjustment was excluded, and the root structure of the questionnaires was kept.

Conclusions: This study supports the value and reliability of ERI-10 and JCQ-20 for measuring job stress among professional drivers. Also, there is a high consistency between both measures of stress, even though they belong to different theoretical conceptions of the phenomenon. In practical settings, these instruments can be useful for occupational researchers and practitioners studying stress-related issues from the perspective of human factors.
\end{abstract}

\footnotetext{
* Correspondence: sergio.useche@uv.es; sausecheh@gmail.com

Précis: This study presents in detail the validation of the ERI (Effort-Reward Imbalance Inventory) and JCQ (Job Content Questionnaire) among professional drivers, two useful tools for assessing job stress from the psychosocial work environment and occupational health perspective.

${ }^{1}$ Faculty of Psychology, University of Valencia, Valencia, Spain

${ }^{2}$ DATS (Development and Advising in Traffic Safety) Research Group, INTRAS

(Research Institute on Traffic and Road Safety), University of Valencia, Valencia, Spain

Full list of author information is available at the end of the article
}

(c) The Author(s). 2021 Open Access This article is licensed under a Creative Commons Attribution 4.0 International License, which permits use, sharing, adaptation, distribution and reproduction in any medium or format, as long as you give appropriate credit to the original author(s) and the source, provide a link to the Creative Commons licence, and indicate if changes were made. The images or other third party material in this article are included in the article's Creative Commons licence, unless indicated otherwise in a credit line to the material. If material is not included in the article's Creative Commons licence and your intended use is not permitted by statutory regulation or exceeds the permitted use, you will need to obtain permission directly from the copyright holder. To view a copy of this licence, visit http://creativecommons.org/licenses/by/4.0/ The Creative Commons Public Domain Dedication waiver (http://creativecommons.org/publicdomain/zero/1.0/) applies to the data made available in this article, unless otherwise stated in a credit line to the data. 
Keywords: Job stress, Job demand-control-model, Effort-reward imbalance, JCQ, ERI, Transportation workers, Professional drivers

\section{Key points}

- This study details the validation of two relevant questionnaires for assessing job stress in professional drivers: Effort-Reward Imbalance (ERI) inventory and Job Content Questionnaire (JCQ).

- These self-reported questionnaires present adequate dimensional structures, factorial weights and internal consistencies among professional drivers.

- The core dimensions and indexes provided by ERI and JCQ have an adequate convergent validity with criterion variables on psychosocial factors at work, health and occupational safety.

- The scales validated can be useful for occupational health research, and for the designing of evidence-based interventions in the industry of transportation.

\section{Background}

Overall, worldwide evidence supports the fact that job stress represents a key psychosocial risk factor in most occupations [1, 2]. Job stress constitutes an issue whose implications involve not only the workers' performance, but their health, safety, and well-being [2-4]. In the particular case of transportation workers, the interest in studying job stress-related dynamics has been gaining ground during the last decade, due to the fact that this type of stress affects not only the workers' domain but, given its predictive role of traffic crashes, threatens the health and welfare of all potential users of the roads $[4,5]$.

Accordingly, different authors consider occupational risks of professional drivers a public health problem $[3,6,7]$. This is due to the fact that, beyond the individual effect of adverse working conditions, workrelated health and behavioral outcomes (e.g., psychological strain, sleep disorders and risky behaviors) may compromise safe driving outcomes. Globally, up to a third of all traffic accidents, which cause 1.3 million deaths a year, involve professional drivers $[8,9]$. Therefore, developing reliable approaches for addressing job stress is an essential first step for designing occupational health and safety-related interventions aimed at reducing the great burden of occupational risk factors in the transportation industry, and their negative impact on community health.

Among all work stress-related measurement approaches, the Effort-Reward Imbalance (ERI) [10] and the Job Demand-Control (JDC) [11] models constitute two relevant perspectives, whose assumptions have been previously tested in several industries, endorsing their reliability, consistency and usefulness for research in occupational health [12-15].

On one hand, the ERI model $[2,16]$ supports the idea that workers perceive a set of extrinsic and intrinsic rewards as a result of the efforts invested in their job. However, an imbalance between the efforts made and the obtained rewards may lead them to a state of "active distress" [17]. On the other hand, the Job Demand-Control model (JDC) [11] defines job strain as a condition in which quantitatively elevated and conflicting demands are combined with scarce decision authority and skill discretion (control). Among transportation workers, typical job features such as repetitive and monotonous work, ergonomic demands, inflexible schedules, shift work and excessive environmental stimuli may enhance the observed high prevalence of job strain, as documented by various recent studies $[5,18,19]$.

In this regard, similar adverse health, performance and safety-related outcomes have been documented for the case of both ERI and JDC models [2, 17, 20], such as cardiovascular diseases $[2,21]$, acute and chronic fatigue [6], poor sleep quality [22, 23], anxiety and depression [24-26]. Moreover, other psychosocial hazardous outcomes at work, such as burnout [27], job dissatisfaction [28] and absenteeism [29] have shown close relationships with workplace stress, implying considerably elevated human and economic costs for organizations and healthcare systems [30].

\section{The current study}

Bearing in mind the aforementioned considerations, and the growing need for validated instruments that address work-related hazards in highly vulnerable workforces, the main purpose of this paper was to assess the psychometric properties, convergent validity and internal consistency of two measures for occupational stress research among professional drivers: the Siegrist's ERI (Effort-Reward Imbalance Inventory) [10] and Karasek's JCQ (Job Content Questionnaire) [11].

Given that many previous experiences applying these questionnaires in different workforces support their reliability, consistency and validity, in addition to their adaptability to different work environments, it was hypothesized that both ERI and JCQ will present a good fit to the data and adequate factor loadings. Also, it was expected that they will keep their generic factor structure, even though some minor variations in the item composition might take place, if we 
consider the set of task-related particularities of professional driving, such as an expected low variability in skill discretion and autonomy within their work environment.

\section{Methods}

\section{Sample}

This research used a convenience sample of Spanish professional drivers from all 17 regions of the country. The sample size was estimated through an a priori lower bound sample size calculation for structural equation models [31, 32]. The minimum sample size for a model with an anticipated effect size of .1 (considered a low effect size), a statistical power level of .8, three latent variables (demands, decision latitude and social support factors of the JCQ), 20 observed variables (JCQ items) and a Probability level of 0.05 , was $n=323$ participants. An attempt was made to at least double this number in order to ensure adequate statistical power for the study (rather than for the sample representativeness), increasing the number of participants up to the final size of $n=726$ individuals, after listwise discarding $28(<4 \%)$ cases due to partial completion of the questionnaire. Also, and although the number of items/variables is not an adequate core criterion to establish minimum sample sizes, the proportionality between the sample size and the questionnaire length was considered, being approximately 7:1 (or seven subjects per questionnaire item), which is higher than the minimum 5:1 usually recommended for EFA/CFA-SEM procedures [33, 34]. However, the survey was not excessively long; it had a total of 106 items, so that respondents did not get tired nor lost motivation during its completion, as suggested in key health research guidelines [35, 36].

The full sample was composed of professional drivers aged between 24 (minimum) and 70 (maximum), with a mean age of $M=47.1(S D=8.05)$ years. Regarding gender, and as it was predictable, we found a huge overrepresentation of male workers in this industry: $98.6 \%$ of them were men and $1.4 \%$ women.

The mean hourly intensity of driving during a week timetable was $M=7.82(S D=1.92)$ hours/day and the average number of weekdays working (driving) was $M=$

Table 1 Demographic and driving work-related information of the study sample

\begin{tabular}{|c|c|c|c|}
\hline Feature & Category & Frequency & Percentage \\
\hline \multirow[t]{2}{*}{ Gender } & Female & 10 & $1.4 \%$ \\
\hline & Male & 713 & $98.6 \%$ \\
\hline \multirow[t]{6}{*}{ Days working (driving) a week } & 3 or less & 8 & $1.1 \%$ \\
\hline & 4 & 21 & $2.9 \%$ \\
\hline & 5 & 493 & $67.9 \%$ \\
\hline & 6 & 162 & $22.3 \%$ \\
\hline & 7 & 21 & $2.9 \%$ \\
\hline & No regularity & 21 & $2.9 \%$ \\
\hline \multirow[t]{5}{*}{ Hours driving per day } & $<5 h$ & 49 & $6.7 \%$ \\
\hline & $5-8 h$ & 387 & $53.3 \%$ \\
\hline & $9-12 \mathrm{~h}$ & 261 & $35.9 \%$ \\
\hline & $>12 \mathrm{~h}$ & 6 & $0.9 \%$ \\
\hline & No regularity & 23 & $3.2 \%$ \\
\hline \multirow[t]{3}{*}{ Shift working } & Yes & 324 & $44.6 \%$ \\
\hline & No & 382 & $52.6 \%$ \\
\hline & Only exceptionally & 20 & $2.8 \%$ \\
\hline \multirow[t]{3}{*}{ Transportation modality } & Passenger & 168 & $23.1 \%$ \\
\hline & Cargo & 521 & $71.8 \%$ \\
\hline & Other & 37 & $5.1 \%$ \\
\hline \multirow[t]{5}{*}{ Type of vehicle } & Urban Bus & 31 & $4.3 \%$ \\
\hline & Intercity Bus & 121 & $16.7 \%$ \\
\hline & Van or smaller company vehicle & 57 & $7.8 \%$ \\
\hline & Long-haul / freight vehicle & 486 & $66.9 \%$ \\
\hline & Other & 31 & $4.3 \%$ \\
\hline
\end{tabular}


$5.23(S D=.69)$ days. As for road crash records, the average number of occupational traffic crashes suffered during the last 2 years, regardless of their severity, was $M=$ $.40(S D=1.04)$. Further key demographic and job-related data of the participants of the study are presented in detail in Table 1.

\section{Study design and procedure}

This was a transversal (or cross-sectional) research. In order to carry out this study, framed within a larger collaborative research project in cooperation with organizations in the field of transportation and with Spanish associations of professional drivers, potential participants were allocated and invited to partake through their organizations or associations. This means that a non-probabilistic (convenience) sampling method was employed, as in other similar studies focused on specific workforces. As for the data collection procedure setting, all partaking drivers were asked to complete the questionnaire throughout a period of approximately 1 hour during their formation courses, as previously agreed by their respective companies; this enhanced the disposition of an adequate physical environment for the task. Also, a member of the research staff was permanently monitoring the completion of the questionnaires, in order to solve potential doubts or answering questions of participants, who were previously informed about the protection of their personal data by means of an informed consent form (see Ethics). Special emphasis was put on the fact that the data would be only used for research and scientific purposes. The overall number of incomplete/illegible (excluded) questionnaires were $<30$ and the response rate was around $80 \%$ and, which means four out of five drivers that were invited accepted to participate and filled out the research questionnaire.

\section{Description of the questionnaire}

For this study, we used a self-report questionnaire that was forward-translated from English to Spanish and backward-translated from Spanish to English by two independent professional translators, in order to ensure the accuracy of the translation, as it is often suggested in literature [35]. Afterwards, both versions of the study questionnaire were reviewed by two experts in the research topic (Expert 1: on job stress measuring, and Expert 2: on psychometrics in occupational health), who approved the final form of the survey to be delivered to participants, as advised by the STROBE (STrengthening the Reporting of OBservational studies in Epidemiology) and COSMIN (COnsensus-based Standards for the selection of health status Measurement INstruments) checklists, created for this purpose [35-38].

The full version of the questionnaire was composed of three core sections:

The first section comprised a) demographic variables, e.g., gender, age, town/city of residence, type of job, and $b$ ) work-related features, e.g., type of vehicle(s) driven at job, transport modalities (cargo, passenger or other), hours driven per day, days working per week, shift-working or stability of work shifts, and occupational driving safety indicators, i.e., traffic crashes suffered along the last 2 years during occupational shifts. It is important to remark that, in the Spanish legislation, accidents suffered during initinere displacements (from the place of residence to work and vice versa) are also considered occupational accidents, so this rate includes both in-itinere and on-duty traffic crashes and it was used as a criterion variable (see Table 6 for more information).

The second part of the questionnaire presented the two questionnaires to validate: firstly, we used the Effort-Reward Imbalance Inventory (ERI) [10] in its short/10-item version, that was previously translated into Spanish, which has already been adapted and used in several applied studies dealing with workers with different occupations, including samples of professional drivers from different countries [39, 40]. The questionnaire is composed of two core sub-scales, used to assess psychosocial, stress-related risk factors at work according to the factors proposed in the Effort-Reward Imbalance model [41]. The model points out the imbalance between two sub-scales as an indicator of job stress: extrinsic effort (commonly labeled as Efforts; 3 items, $\alpha=.74$ original) and perceived rewards (commonly labeled as Rewards; 7 items, $\alpha=.79$ original). Further details on scoring of this version of the ERI are presented in Table 3. Throughout two previous empirical studies, the ERI has shown consistent results and good predictive power for adverse psychosocial and health outcomes among workers, such as an impaired overall mental health status, burnout and musculoskeletal symptoms $[13,42]$. Then, we used the 22-item version of the Job Content Questionnaire (JCQ) [11] in its Spanish version, previously validated by Gómez (2011) among Hispanic workers [43]. This version of the scale, used to assess psychosocial factors at work that could potentially lead to job strain, conceived as the job stress indicator of the Job Demand-Control model, comprises the following subscales: skill discretion (6 items, $\alpha=.50$ original) and decision authority (3 items, $\alpha=.61$ original), whose sum allows for the calculation of the variables "control" ( $\alpha=.65$ original); psychological demands (5 items, $\alpha=.67$ original); 
supervisor/manager support ( 4 items, $\alpha=.78$ original); and peer/co-worker support ( 4 items, $\alpha=.72$ original). Additionally, general social support $(\alpha=.83)$ can be calculated as the sum of peer and supervisor support. Further details on the scoring of this version of the ERI are presented in Table 5. Job strain has been empirically associated with health outcomes of workers belonging to different industries [20, 29] and, more specifically, its predictive value for both health problems [19, 21] and safety records [44-46] has also been assessed among professional drivers.

As for the third part of the questionnaire, and apart from the occupational driving-crash rate, two supplementary questionnaires were chosen as criterion variables, in order to test the convergent validity of ERI and JCQ:

a) The abbreviated version of the Copenhagen Psychosocial Questionnaire III (COPSOQ-III). The COPSOQ series of questionnaires were initially developed by Kristensen, Hannerz, Høgh \& Borg [26] and updated by Nübling et al. [47]. The COPSOQ tool is widely used for workplace psychosocial risk assessment and organizational development. It constitutes a generic instrument, which can be potentially used for all types of jobs, in any industry and for workplaces of different sizes [47]. The third version of the questionnaire was lately validated for Spanish professional drivers by Useche, Montoro, Alonso \& Pastor [46]. For this version, the self-report inventory is composed of 52 items measured on a scale from $1=$ "never/hardly ever" or "to a very small extent", to 5 = "always", or "to a very large extent", that are distributed along various factors or sub-scales:

Demands (F1), composed of 12 items $(\alpha=.92$; example item: "Do you have to work very fast?"); Influence and development (F2), consisting of 6 items ( $\alpha=.85$; example item: "Do you have the possibility of learning 7 new things through your work?"); Interpersonal relations and leadership (F3), containing 13 items ( $\alpha=.91$; example item: "Is there good co-operation between your colleagues at work?'); Job insecurity (F4) composed of 6 items ( $\alpha=$ .85; example item: "Are you worried about new technology making you/your work redundant?"); and Strain - effects and outcomes (F5) consisting of 15 items $(\alpha=.90$; example item: "How often have you thought about giving up your profession?"). Each one of these factors provides a continuous score, obtained through adding the punctuation of their items, and can be treated either as continuous variables or qualitatively analyzed, if the sample is small, or if a case study needs to be performed.

Also, the COPSOQ-III includes an additional item for workers to report their self-rated health status in a raw scale 0 (very bad health status) to 10 (very good health status) [47], that was also incorporated as a criterion variable. b) The short version of the General Health Questionnaire (GHQ-12) [48], a 12-item Likert questionnaire aimed at assessing different symptoms that might potentially affect the mental health of individuals, using four different levels to assess the frequency of each symptom of discomfort ( $1=$ never/rarely; $4=$ very often/always). This scale can be scored in a single factor widely known as psychological distress $(\alpha=.74)$, with the possible values ranging between 12 (very low degree of psychological distress) and 48 (very high psychological distress).

\section{Data processing (statistical analysis)}

Initially, a data curation was performed. As only a very reduced number $(<4 \%)$ of the received forms were incomplete or illegible, only fully filled questionnaires were considered for this study, using listwise deletion for filtering the missing data; although one of the shortcomings of listwise deletion is that it may substantially shorten the sample size (and statistical power could be lost [49]), in this case (i) the ratio of questionnaires with missing data was minimal, and (ii) the sample remained considerably large, as it is mentioned in the sample subsection. Afterwards, a basic data and coding was carried out, allowing us to perform descriptive analytic procedures. The factorial structures of the ERI and JCQ were respectively assessed through Exploratory and Confirmatory Factor Analyses (EFA and CFA, respectively) and sequentially tested. The exploratory analyses used a maximum likelihood (ML) method with Promax oblique rotations (please see Table 7 in Appendix 1 ). As for the CFA, and based on the available theoretical and empirical support on the validated instruments, this study is based on confirmatory models, that entail several advantages as for the management of missing data, categorical and non-normally distributed variables [50]. For descriptive analyses and exploratory analyses, the IBM SPSS software (version 26) was used, while lavaan "latent variable analysis" R-based software (version 0.6-5) was used for specifying and estimating the models. Weighted Least Square Mean and Variance adjusted (WLSMV) estimations were applied, keeping in mind that the data was predominantly ordinal and did not meet multivariate normality.

As suggested by expert studies, the model fit was weighed by means of several (instead of single) estimators [51]: Chi-square $\left(\chi^{2}\right)$, Confirmatory Fit Index (CFI), Normed Fit Index (NFI) and Root Mean Square Error of Approximation (RMSEA). The model fit was founded on the cut-off standards most commonly used in literature: a CFI/NFI higher than .90 and a RMSEA lower than .08 suggest a reasonable model fit. Also, the convergent validity of both questionnaires was tested by means of three selected Criterion Variables (CVs) supported in the literature (see Description of the Questionnaire for further 
information). For this purpose, Spearman's rho (or $r_{s}$ ) bivariate correlations, performed using the full sample, were used to assess the association measures among pairs of study variables, considering their robustness over Pearson's $(r)$ correlations when ordinal values are analyzed [52].

Finally, the reliability (or internal consistency) of the scale and its items was gauged through 1) Cronbach's alpha coefficients $(\alpha)$, and 2) the Composite Reliability Index (CRI), an additional consistency index that ranges between 0 (no consistency) and 1 (total consistency), statistically founded on the factor loadings and residuals observed in the confirmatory results. The use of this second index also helps to overcome some of the traditional gaps of Cronbach's alpha as a single way for assessing scale reliability [53].

\section{Results}

\section{Structural models}

With the aim of understanding the factorial structure of the Spanish versions of the ERI and JCQ, Factor Analyses were performed. First, we tested the fit of the data to an Exploratory Factor Analyses (EFA) for both instruments (item factorial weights are shown in Table 8 in Appendix 1), finding a reasonable adjustment for both ERI ( 2 factors; all item $\lambda s>0.30$; $54.011 \%$ of variance explained) and JCQ (5 factors; $62.03 \%$ of variance explained).

These rotated solutions are interpretable and theoretically sensitive [54]. In particular, the JCQ's five-factor solution results consistent with previous validation studies $[55,56]$, in which there is a general consensus on its factorial structure $[55,57,58]$. Likewise, the ERI bifactorial solution is consistent with the general trend in previous European validation studies [59,60], which for abbreviated versions of the questionnaire coincide in the identification of at least two fixed factors (i.e., effort and rewards). Furthermore, using the EFA scree plots as criteria for factor extraction (see Figs. 3 and 4 in Appendix 1 for plots and exploratory factor loadings), it was found that, in the case of the JCQ, the models with one to five factors produce eigenvalues greater than 1 ; and in the case of the ERI, the bifactorial model is the only one that produces eigenvalues greater than 1 . Taking these theoretical and statistical criteria into account, in this study the JCQ 5-factor solution and ERI 2-factor solution were chosen to test them using CFA.

\section{Effort-reward imbalance inventory (ERI)}

The original structure of the short version of the ERI is composed of two factors: Efforts (F1) and Rewards (F2). Thus, the baseline two-factor model was tested, showing relatively good but improvable fit indexes, with: $\chi^{2}(34)=$ $360.049, p<.001, \quad$ CMIN/DF $=10.590 ; \quad$ RMSEA $=.115$ with 90\% CI of .104-.126; CFI $=.849$; and NFI $=.837$. A close inspection of this baseline two-factor model allowed us to identify a reduced set of very large modification indexes that pointed out a relevant relationship between some items, used for constraining the model. The new simplified model fitted the data reasonably well, presenting the following fit indices: $\chi^{2}(25)=$ $117.780, p<.001, \mathrm{CMIN} / \mathrm{DF}=4.711$; $\mathrm{RMSEA}=.072$ with 90\% CI of .059-.085; CFI $=.957$; and NFI $=.947$. Compared to the baseline model, the final two-factor structure presents a much better fit without the need of deleting questions, bearing in mind both the considerably adequate factor loadings (all $\lambda>0.30$ ) and the reliability scores obtained in the following analysis (see 3.2 Internal consistencies). Table 2 shows the content, descriptive data (average scores and standard deviations), standardized factor loadings and significance levels of each one of the items composing the ERI-10, as it is also presented in Fig. 1.

\section{Scoring and calculation of effort-reward imbalance ratio}

This version of the ERI keeps the item number and basic structure of the previous version, containing 3 items within Efforts - F1, and 7 items within Rewards - F2, that should be computed for calculating the imbalance between Efforts and Rewards. These two root factors of this version of the ERI are calculated as the sum of their respective group of items, once the negative questions had been decoded, as shown in the fourth column of Table 3.

\section{Job content questionnaire (JCQ)}

The original structure of this version of the JCQ is composed of 22 items, distributed in five item-based factors: Skill Discretion (F1), Decision Authority (F2), Psychological Job Demands (F3), Supervisor Support (F4), and Co-worker/Peer Support (F5). Firstly, the baseline fivefactor model was tested using Confirmatory Factor Analysis (CFA), showing considerably adequate, well-fitted indexes, with: $X^{2}(199)=1046.902, p<.001, \mathrm{CMIN} / \mathrm{DF}=$ 5.261; RMSEA $=.077$ with $90 \% \mathrm{CI}$ of $.072-.081$; CFI $=$ .857 ; and NFI $=.831$. Nevertheless, a close inspection of this baseline five-factor model allowed us to detect a short set of very large modification indexes that pointed out a relevant relationship between some items, used for constraining the model. Also, and bearing in mind that the original instrument has 22 items for assessing the aforementioned five main factors, we decided to clear the scale by excluding those items which reported obvious psychometric issues in the measurement of their respective constructs, including those items with factorial loadings $(\lambda)$ under .30 .

CFA outcomes can indicate that a model is not acceptable for reasons such as insignificant indicators 
Table 2 ERI-10 structure. Item content, factor the item belongs to, standardized factor loading ( $\boldsymbol{\lambda}$ ), standard error (S.E.), critical ratios (C.R.) and $p$-values in the retained model

\begin{tabular}{|c|c|c|c|c|c|c|c|c|}
\hline Item & Item Content & Factor & $M^{a}$ & S.D. ${ }^{b}$ & $\lambda$ & S.E. & C.R. & $\mathbf{P}$ \\
\hline ERI1 & I have constant time pressure due to a heavy workload. & Efforts (F1) & 3.03 & .82 & .724 & 0.076 & 13.766 & $<.001$ \\
\hline ERI2 & $\begin{array}{l}\text { I have many interruptions and disturbances while performing } \\
\text { my job. }\end{array}$ & & 2.54 & .80 & .757 & 0.069 & 14.777 & $<.001$ \\
\hline ERI3 & $\begin{array}{l}\text { Over the past few years, my job has become more and more } \\
\text { demanding. }\end{array}$ & & 2.71 & .86 & .668 & 0.067 & 14.418 & $<.001$ \\
\hline ERI4 & $\begin{array}{l}\text { I receive the respect I deserve from my superior or a respective } \\
\text { relevant person. }\end{array}$ & Rewards (F2) & 2.34 & .88 & .725 & 0.061 & 17.042 & $<.001$ \\
\hline $\mathrm{ERI}^{(-)}$ & My job promotion prospects are poor. & & 2.05 & .92 & .321 & 0.059 & 7.849 & $<.001$ \\
\hline $\mathrm{ERI}^{(-)}$ & $\begin{array}{l}\text { I have experienced or I expect to experience an undesirable } \\
\text { change in my work situation. }\end{array}$ & & 2.36 & .94 & .480 & 0.061 & 11.620 & $<.001$ \\
\hline $\mathrm{ERI}^{(-)}$ & My job security is poor. & & 2.57 & .91 & .313 & 0.058 & 7.650 & $<.001$ \\
\hline ERI8 & $\begin{array}{l}\text { Considering all my efforts and achievements, I receive the respect } \\
\text { and prestige I deserve at work. }\end{array}$ & & 2.27 & .87 & .782 & 0.059 & 18.083 & $<.001$ \\
\hline ERI9 & $\begin{array}{l}\text { Considering all my efforts and achievements, my job promotion } \\
\text { prospects are adequate. }\end{array}$ & & 2.28 & .88 & .619 & 0.058 & 14.843 & $<.001$ \\
\hline ERI10 & $\begin{array}{l}\text { Considering all my efforts and achievements, my salary/income is } \\
\text { adequate. }\end{array}$ & & 2.04 & .85 & .722 & 0.056 & 17.029 & $<.001$ \\
\hline
\end{tabular}

Notes: ${ }^{(-)}$Negative Item; ${ }^{\text {a }}$ Arithmetic mean; ${ }^{\text {b }}$ Standard deviation

or items with deficient psychometric adjustment, so it must be modified and improved considering certain factors, such as factor loadings and drawn covariances, and the model's fit to the data should be tested a second time. Accordingly, two items of the F1 (Skill Discretion) were dismissed. The new simplified model fitted the data reasonably well, presenting the following fit indices: $\chi^{2}(153)=477.392, p<.001$, CMIN/DF $=3.120 ; \quad$ RMSEA $=.054$ with $90 \%$ CI of $.049-.060 ; \mathrm{CFI}=.943$; and NFI $=.918$. It is relevant to remark that, compared to the baseline model including these two items, the final five-factor structure with 20 items presents a much better fit, considering both the adequate factor loadings of all the remaining items $(\lambda>0.30)$ and the reliability scores obtained in the next step (see 3.2 Internal consistencies). Table 4 shows the content, descriptive data (average scores and standard deviations), standardized factor loadings and significance levels of each one of the items composing the JCQ-20, as shown in Fig. 2 as well.

\section{Scoring and calculation of the job strain index}

This version of the instrument keeps the same structure as the previous version, and the possible scoring ranges in the Likert scale 1-4 guarantee the parity between Psychological Demands and Control for the calculation of the Job Strain (JS) indicator. This suggests an imbalance between the aforementioned two factors if the JS score is higher than 1.0. Both specific scores in Social Support (from supervisors - F4, and from co-workers - F5) and the general Social

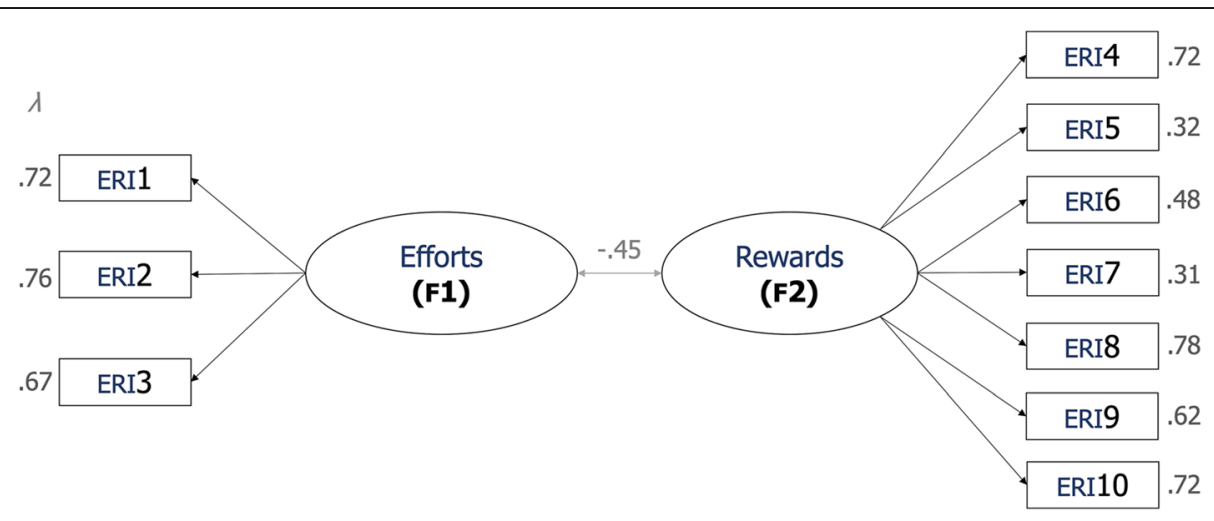

Fig. 1 Standardized parameter estimates. Notes: All estimates were $p<0.001$; the numbers within squares represent the original numbers of the items in the ERI (as shown in Table 2) 
Table 3 ERI-10 factor scoring parameters and variable ranges

\begin{tabular}{|c|c|c|c|c|c|}
\hline Variable/Factor & No. & Number of items & Items involved & Calculation formula & Range \\
\hline \multicolumn{6}{|l|}{ Root Factors } \\
\hline Efforts & $\mathrm{F} 1$ & 3 & $1,2,3$ & $(E R I 1+E R I 2+E R I 3)$ & {$[3-12]$} \\
\hline Rewards & F2 & 7 & $4,5,6,7,8,9,10$ & $(E R I 4+(5-E R I 5)+(5-E R I 6)+(5-E R I 7)+E R I 8+E R \mid 9+E R I 10)^{a}$ & {$[7-28]$} \\
\hline \multicolumn{6}{|c|}{ Effort-Reward Imbalance (ERI) Indicator ${ }^{b}$} \\
\hline Effort-Reward Imbalance (ERI) & F3 & 10 & $\mathrm{~F} 1, \mathrm{~F} 2$ & $K^{*}(F 1 / F 2)=\left((7 / 3)^{*}(F 1 / F 2)\right)^{c}$ & - \\
\hline
\end{tabular}

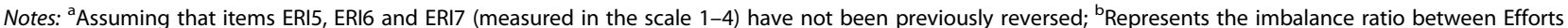
and Rewards, or $E R l$; ${ }^{\mathrm{C}}$ Being $K=$ (\# items on $\mathrm{F} 2 /$ \# items on $\mathrm{F} 1$ )

Support score - F7 can be used for further comparisons, data crossing and further analyses. The raw values of the five root factors of the JCQ-20 are calculated as shown in the fourth column of Table 5.

\section{Internal consistencies}

Alpha estimates were (except for the JCQ's Skill Discretion scale, with $\alpha=.63$, that is acceptable although not optimal) all above the usual $\alpha=.70$ criterion that is a popular rule of thumb advised in many sources as an indicator of adequate internal reliability [61]. Moreover, the Composite Reliability Index (CRI) was also assessed, in order to provide a measure complementary to the
Cronbach's Alpha, showing highly adequate reliabilities for all the three latent constructs addressed by both instruments, as follows:

\section{Reliability and consistency of ERI-10}

In the case of the Effort-Reward Imbalance Inventory (ERI), the following reliability indices were obtained: $\alpha=$ .759 for Efforts (Factor 1), and $\alpha=.780$ for Rewards (Factor 2). The Composite Reliability Index (CRI) of the two factors measured by this version of the ERI were: $\mathrm{CRI}=.956$ for $\mathrm{F} 1$ (Efforts), and $\mathrm{CRI}=.974$ for $\mathrm{F} 2$ (Rewards).

Table 4 JCQ-20 structure. Item content, factor that the item belongs to, standardized factor loading ( $\boldsymbol{\lambda}$ ), standard error (S.E.), critical ratios (C.R.) and $p$-values in the retained model

\begin{tabular}{|c|c|c|c|c|c|c|c|c|}
\hline Item & Item Content & Factor & $M^{a}$ & S.D. ${ }^{b}$ & $\lambda$ & S.E. & C.R. & $\mathbf{P}$ \\
\hline$\overline{J C Q 1}$ & I need to be learning new things. & \multirow{4}{*}{$\begin{array}{l}\text { Skill Discretion } \\
(F 1)\end{array}$} & 3.28 & .70 & .32 & .05 & 7.07 & $<.001$ \\
\hline $\mathrm{JCQ} 2$ & I need to be creative. & & 2.85 & .78 & .42 & .24 & 6.19 & $<.001$ \\
\hline JCQ5 & There is variety in the activities I do. & & 2.70 & .81 & .50 & .28 & 6.53 & $<.001$ \\
\hline JCQ7 & I have the opportunity to develop my own skills. & & 2.78 & .82 & .78 & .40 & 7.07 & $<.001$ \\
\hline JCQ3 & I can make many decisions by myself. & \multirow{3}{*}{$\begin{array}{l}\text { Decision Authority } \\
\text { (F2) }\end{array}$} & 3.03 & .83 & .49 & .04 & 11.97 & $<.001$ \\
\hline $\mathrm{JCQ} 4$ & I have a lot of freedom to decide how to do my job. & & 2.67 & .87 & .58 & .06 & 12.58 & $<.001$ \\
\hline JCQ6 & My opinions count a lot. & & 2.55 & .89 & .87 & .16 & 11.97 & $<.001$ \\
\hline JCQ8 & I have to work very fast. & \multirow{5}{*}{$\begin{array}{l}\text { Psychological Job } \\
\text { Demands } \\
\text { (F3) }\end{array}$} & 2.88 & .86 & .69 & .10 & 12.41 & $<.001$ \\
\hline JCQ9 & I have to work very hard. & & 3.01 & .82 & .71 & .06 & 15.63 & $<.001$ \\
\hline JCQ10 & I am asked to do an excessive amount of work. & & 2.64 & .92 & .78 & .07 & 16.99 & $<.001$ \\
\hline JCQ11(-) & I have enough time to do my job. & & 2.40 & .78 & .47 & .06 & 10.61 & $<.001$ \\
\hline JCQ12 & I have to respond to contradictory orders. & & 2.58 & .89 & .53 & .06 & 12.41 & $<.001$ \\
\hline JCQ13 & $\begin{array}{l}\text { My boss or supervisor cares about the economic } \\
\text { well-being of the staff in charge. }\end{array}$ & \multirow[t]{4}{*}{$\begin{array}{l}\text { Supervisor Support } \\
\text { (F4) }\end{array}$} & 2.26 & .96 & .79 & .05 & 21.02 & $<.001$ \\
\hline$J C Q 14$ & My boss or supervisor pays attention to what I say. & & 2.59 & .90 & .88 & .04 & 24.35 & $<.001$ \\
\hline$J C Q 15$ & My supervisor or boss helps to get the job done. & & 2.76 & .84 & .75 & .04 & 20.97 & $<.001$ \\
\hline JCQ16 & $\begin{array}{l}\text { My supervisor is successful in getting you to work } \\
\text { well in a team. }\end{array}$ & & 2.66 & .87 & .80 & .04 & 21.02 & $<.001$ \\
\hline JCQ17 & The people I work with are competent to do their job. & \multirow{4}{*}{$\begin{array}{l}\text { Co-worker Support } \\
\text { (F5) }\end{array}$} & 2.87 & .76 & .66 & .07 & 13.85 & $<.001$ \\
\hline JCQ18 & The people I work with are interested in me personally. & & 2.50 & .87 & .88 & .09 & 16.34 & $<.001$ \\
\hline JCQ19 & My coworkers are friendly. & & 2.98 & .69 & .63 & .06 & 14.50 & $<.001$ \\
\hline JCQ20 & My colleagues help to get the job done. & & 2.87 & .77 & .72 & .08 & 13.85 & $<.001$ \\
\hline
\end{tabular}

Notes: ${ }^{(-)}$Negative Item; $^{\text {a }}$ Arithmetic mean; ${ }^{\text {b }}$ Standard deviation 


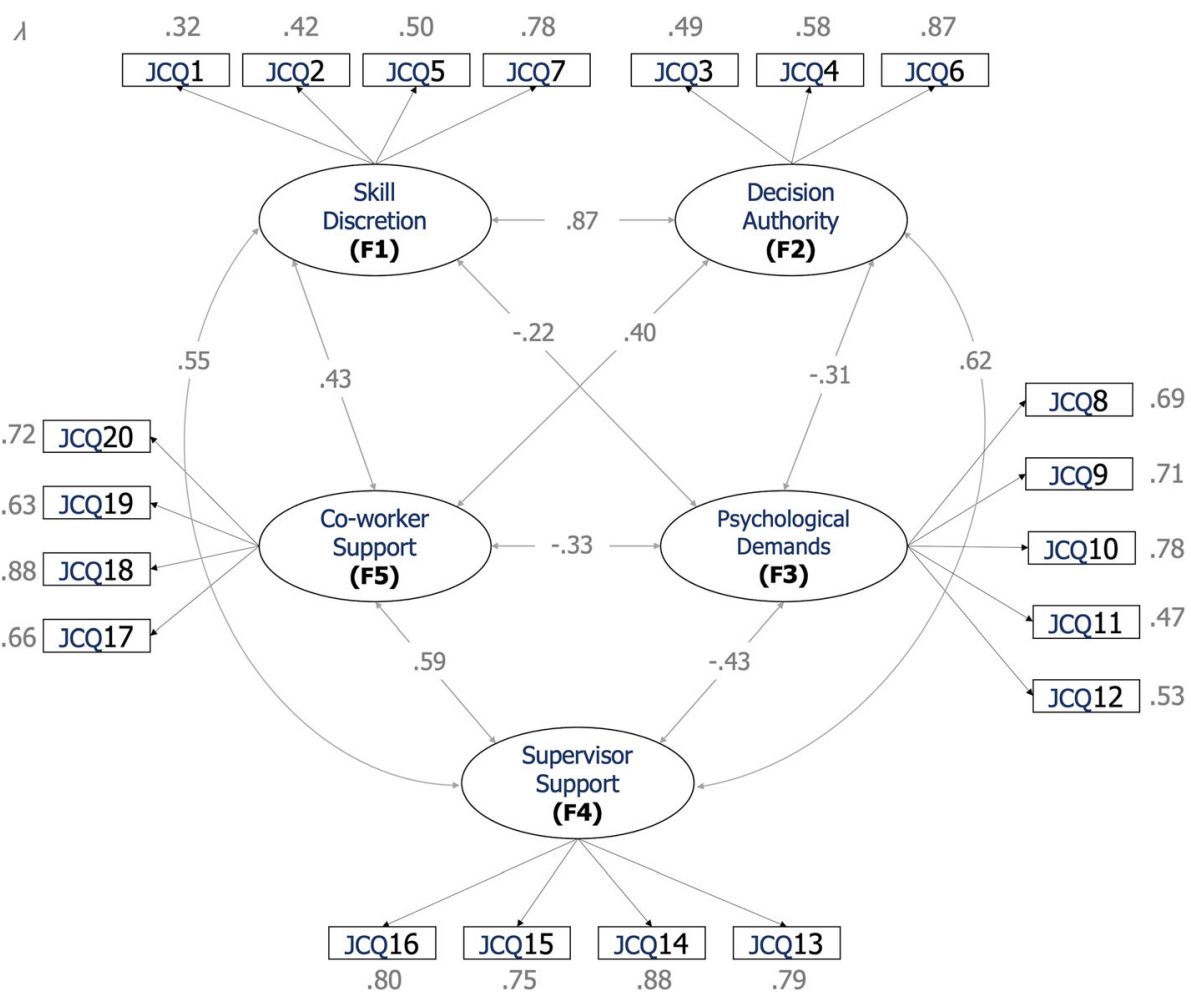

Fig. 2 Standardized parameter estimates. Notes: All estimates were $p<0.001$; the numbers within squares represent the numbers of the items in the shortened version of the JCQ (as shown in Table 4)

\section{Reliability and consistency of JCQ-20}

As for the Job Content Questionnaire (JCQ), we found: $\alpha=.633$ for Skill Discretion (Factor 1); $\alpha=.725$ for Decision Authority (Factor 2); $\alpha=.761$ for Psychological Job Demands (Factor 3); $\alpha=.886$ for Supervisor Support (Factor 4); and $\alpha=.828$ for Co-worker/Peer Support (Factor 5). The Composite Reliability Index (CRI) of the five factors assessed by this version of the JCQ were: $\mathrm{CRI}=.809$ for $\mathrm{F} 1$ (Skill Discretion), $\mathrm{CRI}=.809$ for $\mathrm{F} 1$ (Skill Discretion), CRI = .934 for F2 (Decision Authority), CRI $=.965$ for F3 (Psychological Job Demands), CRI = .983 for F4 (Supervisor Support), and CRI $=.966$ for F5 (Co-worker/Peer Support), showing suitable reliabilities for all the constructs.

Table 5 JCQ-20 factor scoring parameters and variable ranges

\begin{tabular}{|c|c|c|c|c|c|}
\hline Variable/factor & No. & Number of items & Items /factors involved & Calculation formula & Range \\
\hline \multicolumn{6}{|l|}{ Root Factors } \\
\hline Skill Discretion & F1 & 4 & $1,2,5,7$ & $((J C Q 1+J C Q 2+J C Q 5+J C Q 7) * 3)$ & [12-48] \\
\hline Decision Authority & $\mathrm{F} 2$ & 3 & $3,4,6$ & $\left((J C Q 3+J C Q 4+J C Q 6)^{*} 4\right)$ & [12-48] \\
\hline Psychological Demands & F3 & 5 & $8,9,10,11,12$ & $((J C Q 8+J C Q 9) * 3)+\left((J C Q 10+J C Q 12)^{*} 3\right)+\left((5-J C Q 11)^{*} 2\right)^{a}$ & [12-48] \\
\hline Supervisor Support & F4 & 4 & $13,14,15,16$ & (JCQ13 + JCQ14 + JCQ15 + JCQ16) & [4-16] \\
\hline Co-worker Support & F5 & 4 & $17,18,19,20$ & (JCQ17 + JCQ18 + JCQ19 + JCQ20) & [4-16] \\
\hline \multicolumn{6}{|l|}{ Composed Factors ${ }^{b}$} \\
\hline Control & F6 & 7 & $\mathrm{~F} 1, \mathrm{~F} 2$ & $F 1+F 2$ & [24-96] \\
\hline Social Support & F7 & 8 & $\mathrm{~F} 4, \mathrm{~F} 5$ & $\mathrm{~F} 4+\mathrm{F} 5$ & [8-32] \\
\hline \multicolumn{6}{|l|}{ Job Strain (JS) Indicator } \\
\hline Job Strain & F8 & 12 & $\mathrm{~F} 3, \mathrm{~F} 6$ & $\left(F 3^{*} 2\right) / F 6$ & - \\
\hline
\end{tabular}

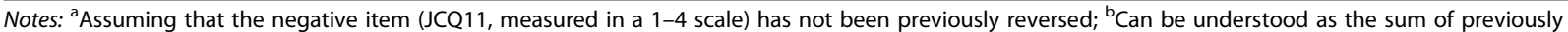
calculated factors with acceptable psychometric properties; ' ${ }^{\mathrm{A}}$ resulting value higher than 1.0 indicates imbalance between Demands and Control, or Job Strain 
Factor correlations and convergent validity

In order to test the convergent validity of the ERI-10 and JCQ-20, all factors of both scales were contrasted with criterion variables (CVs), in order to assess their relationships (in terms of significance and association) in the glance of the existing evidences. Criterion variables were divided in three sets: the five factors of the validated version of COPSOQ-III $\left(\mathrm{CV}^{\mathrm{a}-\mathrm{e}}\right)$; two healthrelated indicators: the psychological distress score of the GHQ-12 $\left(\mathrm{CV}^{\mathrm{f}}\right)$ and the self-rated health status item of COPSOQ-III $\left(\mathrm{CV}^{\mathrm{g}}\right)$; the number of occupational driving accidents suffered during the last two years $\left(\mathrm{CV}^{\mathrm{h}}\right)$. Based on the theoretical considerations and previous empirical evidence retrieved during the literature review (see Background), the main hypotheses for the correlations between ERI/JCQ factors and the criterion variables were:

(i) ERI vs. JCQ: ERI's Efforts subscale will positively correlate to JCC's Demands, and ERI's Rewards will positively correlate to JCQ's Control subscale. Also, the job stress indexes of both models will have a positive and significant correlation.

(ii) ERI/JCQ and CVs: The job stress indexes of both models (Effort-Reward Imbalance and Job Strain) will have correlations similar to the criterion variables, being significant and positive for $\mathrm{CV}^{\mathrm{a}}, \mathrm{CV}^{\mathrm{d}}, \mathrm{CV}^{\mathrm{e}}, \mathrm{CV}^{\mathrm{f}}$ and $\mathrm{CV}^{\mathrm{h}}$, and significant and negative for $\mathrm{CV}^{\mathrm{b}}, \mathrm{CV}^{\mathrm{c}}$ and $\left(\mathrm{CV}^{\mathrm{g}}\right)$. Almost all the Bivariate correlations between pairs of factors were, as hypothesized, statistically significant at level $p<.001$, directionally coherent and considerably large. Table 3 presents in detail the Pearson's correlational coefficients ( $\sigma$ 's) among the full set of variables.

\section{Convergent validity of ERI-10}

The correlation between Efforts and Rewards $\left(\sigma_{s}=\right.$ $\left.-.444^{* *}\right)$ was negative and significant, and the correlation between Efforts and E-R Imbalance (ERI) was positive $\left(\sigma_{s}=.826^{* * *}\right)$. Also, ERI and Rewards had a significant and negative correlation $\left(\sigma_{s}=-.851^{* * *}\right)$, as hypothesized.

For what concerns the Job Demand-Control model (Karasek's JCQ factors), all the relationships between the main factors of both scales were coherent and significant. Scores on Efforts and ERI were, respectively, positively correlated to Psychological Demands $\left(\sigma_{s}=.624^{* * *}\right.$ and $\left.\sigma_{s}=.649 \%\right)$ and Job Strain $\left(\sigma_{s}=.466^{* * *}\right.$ and $\left.\sigma_{s}=.619^{* * *}\right)$, and negatively correlated to Control $\left(\sigma_{s}=-.099^{*}\right.$ and $\left.\sigma_{s}=-.277^{* * * *}\right)$ and Social Support $\left(\sigma_{s}=-.282^{* * *}\right.$ and. $\left.\sigma_{s}=-.539^{* * *}\right)$. On the other hand, Rewards' scores were positively associated with Control $\left(\sigma_{s}=.402^{* *}\right)$ and Social Support $\left(\sigma_{s}=.629^{* *}\right)$, and negatively with Psychological Demands $\left(\sigma_{s}=-.468^{* * *}\right)$ and the Job Strain indicator $\left(\sigma_{s}=-.565^{* * *}\right)$.

As for the criterion variables, both Efforts and ERI (Imbalance) were found positively correlated to COPSOQ's Demands $\left(\sigma_{s}=.628^{* * *}\right.$ and $\left.\sigma_{s}=.695^{* *}\right)$, Job Insecurity $\left(\sigma_{s}=\right.$
$.257^{* * *}$ and $\left.\sigma_{s}=.342^{* * *}\right)$ and Strain $\left(\sigma_{s}=.475^{* *}\right.$ and $\sigma_{s}=$ $.679 * \%)$, and negatively to Influence and Development $\left(\sigma_{s}=\right.$ $-.115^{* * *}$ and $\left.\sigma_{s}=-.329^{* *}\right)$ and Leadership $\left(\sigma_{s}=-.432^{* * *}\right.$ and $\left.\sigma_{s}=-.651^{* *}\right)$, while Rewards were negatively associated with Demands $\left(\sigma_{s}=-.548^{* * *}\right)$, Job Insecurity $\left(\sigma_{s}=-.312^{* * *}\right)$ and Strain $\left(\sigma_{s}=-.667^{* * *}\right)$, and positively correlated to Influence and Development $\left(\sigma_{s}=.431^{* *}\right)$ and Leadership $\left(\sigma_{s}=\right.$ $\left..667^{* * *}\right)$. Moreover, occupational traffic crashes were positively correlated to the ERI ratio $\left(\sigma_{s}=.084^{*}\right)$ and negatively to Rewards $\left(\sigma_{s}=-.093^{*}\right)$, being all the directions of significant correlations coherent with theoretical assumptions.

\section{Convergent validity of JCQ-20}

The three main indicators of the Job Demand-Control (JDC) model presented significant and coherent correlations among them: Psychological Demands were negatively associated to Control $\left(\sigma_{s}=-.141^{* * *}\right)$ and positively to Job Strain (JS; $\left.\sigma_{s}=.791^{* *}\right)$, while Control showed a negative correlation to JS $\left(\sigma_{s}=-.673^{* *}\right)$.

As for the set of criterion variables used, Psychological Demands shown a positive relationship to COPSOQ's Demands $\left(\sigma_{s}=.611^{* * *}\right)$ and Strain $\left(\sigma_{s}=.517^{* * *}\right)$ subscales. On the other hand, Control had a positive correlation with both Influence and Development $\left(\sigma_{s}=.513 * \%\right)$ and Leadership $\left(\sigma_{s}=.422^{* * *}\right)$. The Karasek's Job Strain (JS) index positively correlated to the COPSOQ's Strain subscale $\left(\sigma_{s}=.609^{* *}\right)$, the Psychological Distress indicator of the GHQ $\left(\sigma_{s}=.365^{* *}\right)$, and negatively to the selfreported Health Status $\left(\sigma_{s}=-.208^{* *}\right)$. Finally, occupational traffic crashes were significantly and negatively associated to Control $\left(\sigma_{s}=-.133^{* * *}\right)$, and positively with both Psychological Demands $\left(\sigma_{s}=.088^{*}\right)$ and the Job Strain index $\left(\sigma_{s}=.170^{* * *}\right)$, as theoretically expected. The full set of bivariate correlations is available at Table 6 .

\section{Discussion}

This study pursued the main aim of assessing the psychometric properties, convergent validity and internal consistency of two measures of occupational stress research (ERI and JCQ) among professional drivers. Overall, the outcomes of this empirical research confirm that both self-report tools keep a fairly adjusted factor configuration, adequate psychometric properties and convergent validity in regard to similar measures and complementary factors, such as health indicators and road safety outcomes, thus guaranteeing the methodological value of the validated versions of these questionnaires for their application among active workers of the transportation industry.

Precisely, the introduction of this article remarked the scarcity of validated (and reliable) self-report tools to address job stress from the perspective of psychosocial factors at work in highly vulnerable populations such as professional drivers. This gives a higher methodological value to 


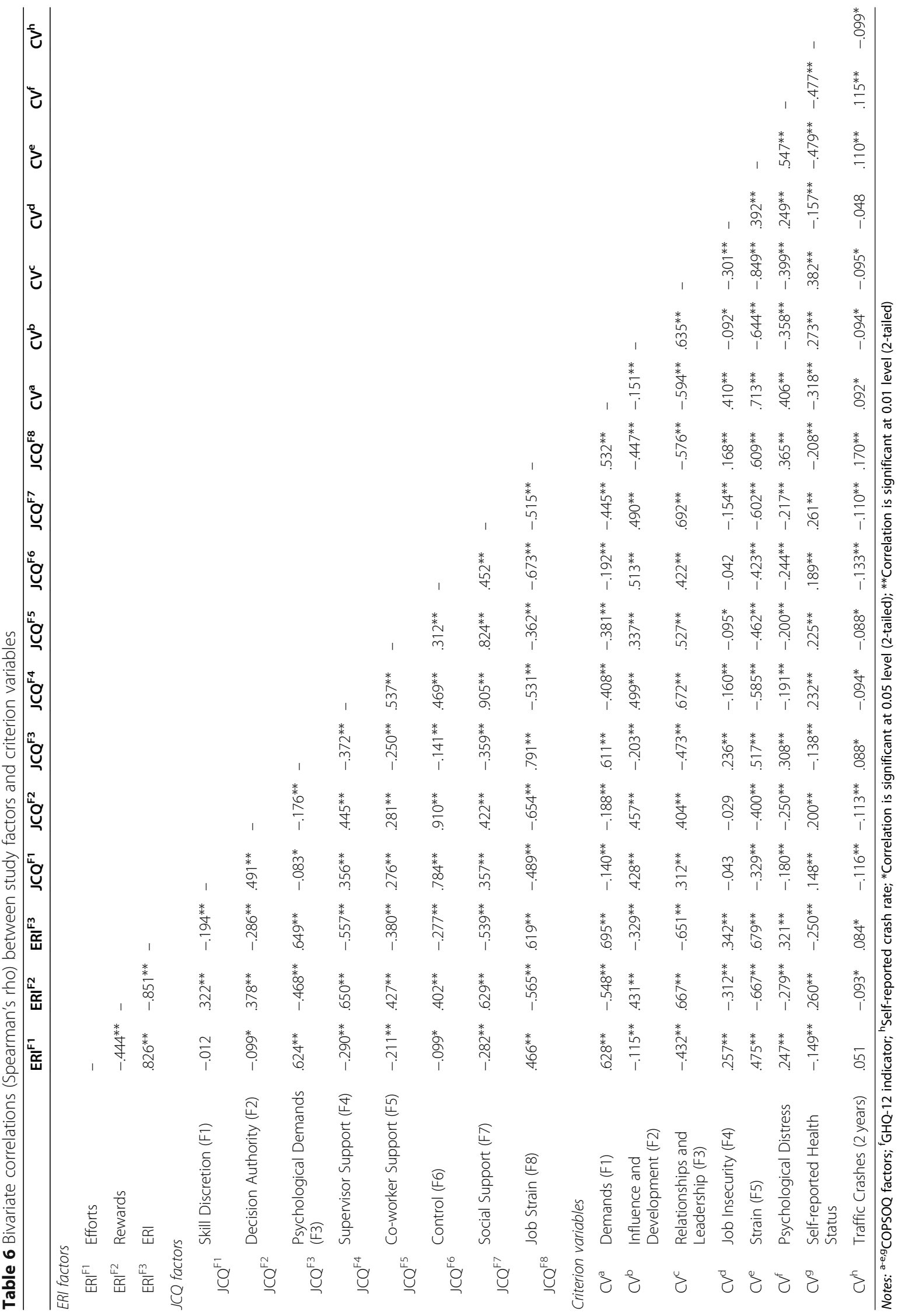


the ones presented in this paper, if their short length, easy application and fair psychometric properties are considered. In regard to the validity of the ERI-10 and JCQ-20 factors, it is worth highlighting the high theoretical consistency of the original structure of both instruments with their validated version, highlighting the following particularities:

\section{Effort-reward imbalance inventory (ERI)}

In the case of the ERI, all the lambda $(\lambda)$ values, indicating the factor loading of each item, were higher than .30 (defined as a cut-off point). Also, the tested two-factorial model has shown a commendable fit, considering the model fit indices (i.e., $\mathrm{CMIN} / \mathrm{DF}=4.711$; $\mathrm{RMSEA}=.072$ - CI [.059-.085]; CFI = .957; and NFI = .947) [51].

Regarding the convergent validity of ERI factors (for guidance please see Table 6), this is an issue that has to be analyzed in the glance of other previous studies dealing with job stress in different populations, but especially with professional drivers, that document the relationship between the two root factors (Efforts and Rewards) and the Effort-Reward Imbalance ratio provided by the scale. In the first place, it is worth discussing some key findings in the Efforts subscale (F1). Scores in Efforts (measured by different versions of the ERI questionnaire) have been associated with health indicators of workers in different previous studies, also finding a negative relationship between job efforts and both mental and physical health issues [45, 62, 63].

Besides, Efforts were negatively associated to Rewards and positively to the ERI ratio, as observed in other studies $[45,63]$. Further, a recent systematic review on the Effort-Reward Imbalance among health workers, performed by Nguyen Van et al. [64], found that, in more than 40 different empirical studies, Rewards (F2) are often perceived as lower than the efforts put in the development of their job tasks, suggesting the need of empirically-based interventions on workplace environmental conditions and job stress. Finally, the convergent validity of the three factors analyzed in the instrument was satisfactorily tested through the assessment of significant and coherent correlations with criterion variables, in accordance with the previous empirical sources of evidence, in terms of: a) job stress measured through other similar inventories, such as the JCQ and COPSOQ $[47,65], b)$ physical and mental health issues [13, 42, $47]$, and $c$ ) occupational accidents $[39,66]$.

\section{Job content questionnaire (JCQ)}

As for the JCQ, the baseline model has displayed a relatively good (but improvable) structure that showed substantial improvements once two items from the Skill Discretion subscale, that presented lambda values <.03 (low factor loadings), were deleted. This led to a retained model with highly suitable indices $(\mathrm{CMIN} / \mathrm{DF}=3.120 ; \mathrm{RMSEA}=.054-$ CI $[.049-.060]$; CFI $=.943$; and NFI $=.918)$, suggesting an optimal fit to the data.

As for the convergent validity of the JCQ, the associations found between JDC model's main subscales and variables measured through similar and/or complementary instruments show coherence with the theoretical assumptions followed by our study, and further empirical findings provided by previous studies in the field. First of all, scores in Psychological Demands were inversely associated with Control, and positively with both COPSOQ's Demands subscale and the Job Strain (JS) index, that is the stress indicator of the model $[3,11]$. JS is also positively correlated to the scores obtained in the Strain subscale of COPSOQ, a directly convergent measure.

Moreover, higher scores in the JS index have shown to be associated to poorer outcomes in terms of mental health assessed through questionnaire-based methods, such as different versions of the GHQ [67-69] and other self-reported measures aimed at assessing the health status of workers [70-72], keeping the same directional associations than the found in this study. Also, previous research based in cohort studies have also documented significant association between (and even a predictive value of) Job Strain and, e.g., coronary heart disease [2], type-II diabetes [73, 74] and musculoskeletal symptoms $[15,75]$, that makes sense if the fact that work environment of professional drivers is also characterized by continuous physical and ergonomic demands is considered $[18,39,46,76]$. Lastly, the number of occupational accidents suffered "at the wheel" by professional drivers has shown a significant association to Job Strain. This is, perhaps, one of the most frequently empirical finding in studies using approaches similar to Karasek's JDC in professional drivers, in terms of driving performance and occupational safety $[3,19,39]$.

It is also important to point in the fact that, given the structural modifications performed on the JCQ (originally containing other two items that were dismissed), the scoring methodology for calculating the Control (F6) and the Job Strain index (JS; F8) has been successfully adapted to the item ratio between F1 (Skill Discretion) and F2 (Decision Authority), and between F6 (Control) and F3 (Demands), necessarily being 1:1 for the calculation of the Job Strain index.

\section{Limitations of the study and further research}

Although this research used a considerably large (although not representative) study sample, the statistical parameters and model fit coefficients were adequately verified, and the quality and value of the questionnaires had been previously supported by many empirical studies, some both methodological and qualitative biasing 
sources should be considered. Firstly, the research was carried out by means of self-report-based data, and several studies have shown how self-report measures may carry different biases, such as acquiescent answers (i.e., the total agreement of participants with the presented questions), social desirability and lack of sincerity, especially considering that most of the questionnaires were applied at the workplace, in the companies where the drivers were working. Furthermore, positive/negative affects/mood may impact the response style of participants, especially when addressing issues that may seem sensitive, such as health issues [77] and occupational traffic crashes, even when responding to anonymous questionnaires, as pointed out by Chai et al. [78] and Af Wåhlberg [79] in previous studies dealing with drivers and their road safety outcomes.

Regarding the questionnaire contents, it is worth remarking that, although standardized scales such as the ERI and JCQ (in their different versions) have a demonstrated to be valuable for measuring psychosocial jobrelated factors in different occupational groups, they fail to address specific stressors and hazardous working conditions that are particular to each profession. Thus, it is advisable to use these tools together with an assessment of the specific (e.g.) stressors, demands and reward modalities of the job, perhaps adding additional short scales and/or qualitative questions that may strengthen interpretations and outcome comparisons, as performed in recent research carried out with professional drivers [80]. Additionally, the authors would like to promise that they will consider all the issues that cannot be fixed a posteriori in this study for further ones.

Finally, this study used a transversal (or cross-sectional) design, which means that the outcomes are obtained from a single measurement moment. Although it methodologically allows for the fulfillment of the study aim, the use of multiple measures may contribute to test the stability, consistency and invariance of the instrument over time (e.g., test-retest reliability), strategy that (even though encompassing higher efforts and further measurements) may represent further insights on the study of psychosocial factors at work following the ERI and JCQ approaches.

\section{Conclusion}

The findings of this study support the hypothesis that the validated versions of both the ERI and JCQ scales, used for assessing job stress from different theoretical approaches, present adequate structural, psychometric and practical features; this makes them suitable for being applied to the study of the phenomenon among professional drivers, as well as workers employed in other similar occupations and facing similar taskrelated factors. Such as the ones addressed by the ERI and JDC models (for instance, excessive efforts, psychological demands, time pressure, and lack of rewards and/or social support). Furthermore, the validated scales keep an adequate convergent validity with criterion variables extracted from similar measures (such as the COPSOQ-III and the GHQ) and occupational (road) safety indicators.

Also, it is important to remark, given both the extensive previous background that exists in this regard and the results of this study, that occupational stress research and intervention can be a useful step to strengthen the road safety outcomes of professional drivers, that nowadays constitute a public health concern. Thus, and keeping in mind the reduced length of ERI-10 and JCQ-20, and several other studies supporting their scientific value, these questionnaires can be useful for performing occupational research focused on psychosocial factors at work, and for designing evidencebased interventions aimed at improving the environmental conditions of the job, as well as the health and safety outcomes of workers in this hazardous industry.

\section{Application (practical implications)}

This study provides the validated versions of two widely used self-report-based psychosocial research tools for assessing job stress, with an adapted structure, for their using among professional drivers: Siegrist's ERI and Karasek's JCQ.

The shortened versions of these instruments, that present fair psychometric properties and convergent validity, can be useful for occupational researchers and practitioners studying stress-related issues from the perspective of human factors at occupational and public health settings.

\section{Appendix 1 Exploratory Factor Analysis: Item factor weights for ERI and JCQ}

Table 7 Exploratory Factor Analysis (EFA): Item factor loadings for the Effort-Reward Imbalance (ERI) inventory - rotated matrix (Promax)

\begin{tabular}{lll}
\hline ERI Item & Efforts & Rewards \\
\hline ERI2 & .802 & -.213 \\
ERI1 & .745 & -.273 \\
ERI3 & .706 & -.136 \\
ERI10 & -.303 & .824 \\
ERI8 & -.389 & .815 \\
ERI4 & -.287 & .778 \\
ERI9 & -.242 & .757 \\
ERI6 & -.485 & .695 \\
ERI7 & -.362 & .592 \\
ERI5 & -.299 & .463 \\
\hline
\end{tabular}


Table 8 Exploratory Factor Analysis (EFA): Item factor loadings for the Job Content Questionnaire (JCQ) - rotated matrix (Promax)

\begin{tabular}{|c|c|c|c|c|c|}
\hline JCQ Item & Supervisor Support & Co-worker Support & Psychological Job Demands & Decision Authority & Skill Discretion \\
\hline JCQ14 & .883 & .437 & -.273 & .419 & .152 \\
\hline JCQ15 & .857 & .416 & -.261 & .393 & .170 \\
\hline JCQ16 & .854 & .507 & -.329 & .376 & .208 \\
\hline JCQ13 & .846 & .482 & -.317 & .388 & .209 \\
\hline JCQ19 & .450 & .844 & -.174 & .218 & .140 \\
\hline JCQ20 & .391 & .828 & -.175 & .189 & -.016 \\
\hline JCQ18 & .510 & .827 & -.274 & .271 & .223 \\
\hline JCQ17 & .364 & .743 & -.196 & .244 & .224 \\
\hline JCQ9 & -.144 & -.132 & .829 & -.026 & .017 \\
\hline JCQ8 & -.385 & -.332 & .806 & -.270 & .057 \\
\hline JCQ10 & -.197 & -.078 & .805 & -.090 & .132 \\
\hline JCQ12 & -.316 & -.277 & .593 & -.301 & .199 \\
\hline JCQ11 & .212 & .163 & -.295 & .016 & .170 \\
\hline JCQ3 & .313 & .300 & -.231 & .787 & .122 \\
\hline JCQ6 & .555 & .291 & -.209 & .784 & .314 \\
\hline JCQ4 & .210 & .067 & .018 & .741 & .148 \\
\hline JCQ2 & .169 & .089 & .104 & .224 & .789 \\
\hline JCQ1 & .311 & .236 & -.163 & .456 & .739 \\
\hline JCQ5 & .142 & .115 & .063 & .106 & .716 \\
\hline JCQ7 & .208 & .213 & -.080 & .424 & .562 \\
\hline
\end{tabular}




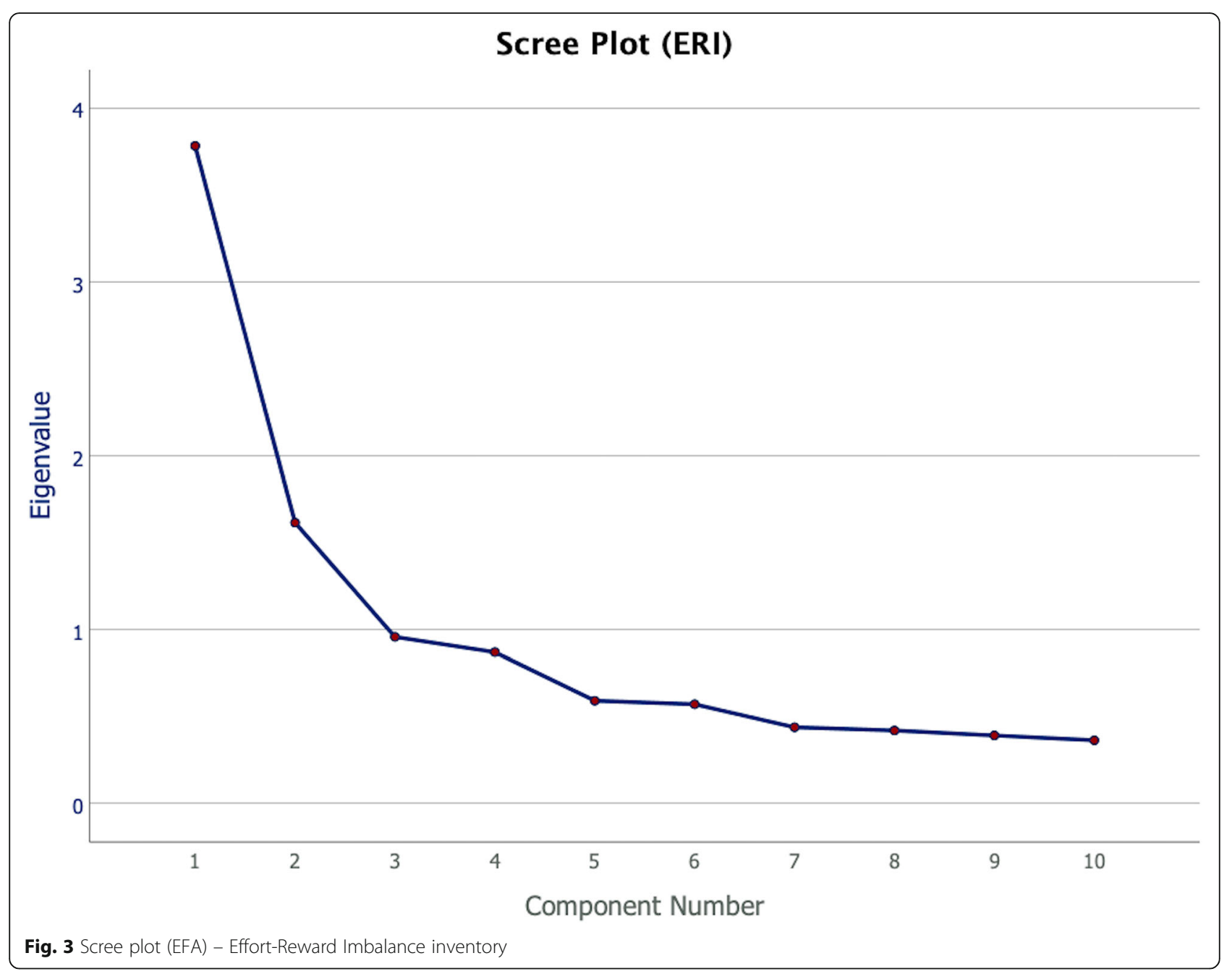




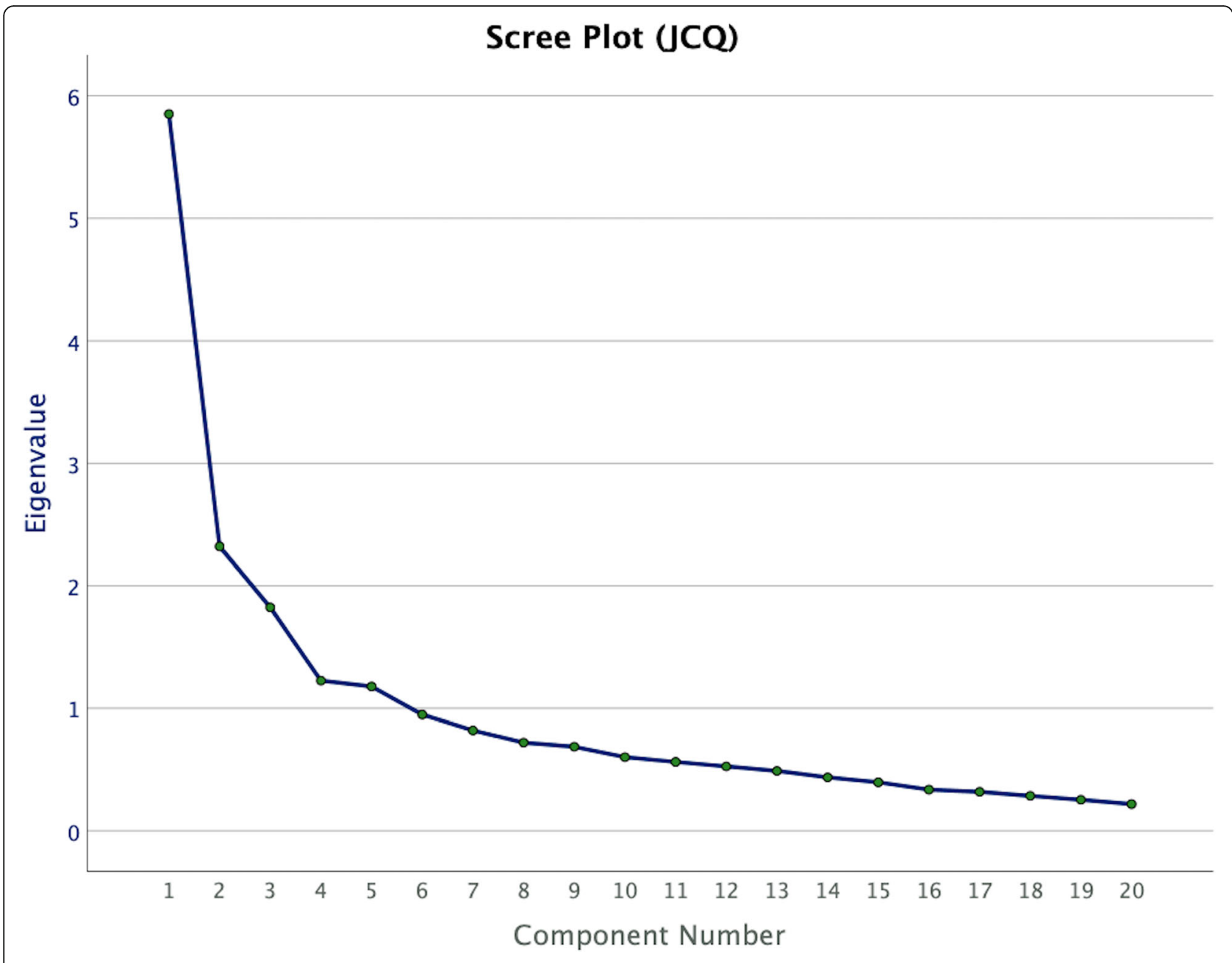

Fig. 4 Scree plot (EFA) - Job Content Questionnaire

\section{Abbreviations}

JCQ: Job Content Questionnaire; JDC: Job Demand-Control (model); JS: Job Strain (job stress indicator of the JDC model); ERI: Effort-Reward Imbalance (model and questionnaire); COPSOQ: Copenhagen Psychosocial

Questionnaire; GHQ: General Health Questionnaire

\section{Acknowledgements}

The authors of the study would like to acknowledge our research participants, aides-de-camp and third stakeholders partaking in the collection of the data and/or advising us in the use of the research tools, such as the Stress and Health research group, led by Dr. Viviola Gómez and the University Research Institute of Human Resources Psychology, Organizational Development and Quality of Working Life research group, led by Dr. José María Peiró, for their expert inputs. Special thanks to FENADISMER (Spanish National Federation of Transport Associations) and ALSA Group for their collaboration in our sample gathering tasks. Specifically, thanks to Javier Gené-Morales (ORCID: 0000-0002-5901-5245) for his technical contributions to the study, and to Runa Falzolgher for the professional edition given to the final version of the paper.

\section{Authors' contributions}

SAU: Conceptualization, Methodology, Data curation, Data analysis, Investigation, Writing- Original draft preparation, Writing- Reviewing and Editing. FA: Visualization, Supervision, Software. BC: Data curation, Data analysis, Writing- Original draft preparation, Writing- Reviewing and Editing. LM: Conceptualization, Software, Supervision. JL:
Methodology, Investigation, Writing- Reviewing and Editing of the revised version of the paper. The authors read and approved the final manuscript.

\section{Authors' information}

Dr. Sergio A. Useche (ORCID: 0000-0002-5099-4627).

Senior researcher (Research Institute in Traffic and Road Safety - INTRAS) and professor at the Faculty of Psychology of the University of Valencia (Spain). Ph.D. from the University of Valencia (Spain).

Dr. Francisco Alonso (ORCID: 0000-0002-9482-8874).

Professor at the University of Valencia (Valencia, Spain). Director of the University Research Institute in Traffic and Road Safety (INTRAS) and the DATS research group. Ph.D. from the University of Valencia (Spain).

Dr. Boris Cendales (ORCID: 0000-0002-6904-7339).

Associate professor and researcher at El Bosque University (Bogotá,

Colombia). Ph.D. from Los Andes University (Colombia).

Dr. Luis Montoro (ORCID: 0000-0003-0169-4705).

Full professor at the University of Valencia (Valencia, Spain). Director of the FACTHUM. Lab research group, University Research Institute in Traffic and Road Safety (INTRAS). President of Honor of the Spanish Foundation for Road Safety. Ph.D. from the University of Valencia (Spain). Dr. Javier Llamazares (ORCID: 0000-0001-8231-8677).

Executive Director of the Spanish Road Safety Foundation (FESVIAL). Professor and researcher at the ESIC Business \& Marketing School. Ph.D. from the University of Valencia (Spain). 


\section{Funding}

The current study did not receive any funding from neither public, commercial, nor not-for-profit agencies or entities.

\section{Availability of data and materials}

The data that support the findings of this study are available from the corresponding author (S.A.U.), upon reasonable request.

\section{Declarations}

\section{Ethics approval and consent to participate}

This study was approved by the Social Science in Health Research Ethics Committee of the University of Valencia, thus granting that it responds to the general ethical principles, and its accordance with the Declaration of Helsinki (IRB number H1517828884105) was certified. In this research, personal and/or confidential data were not retrieved, with the aim of avoiding any potential risk for the integrity of the participants. Furthermore, an Informed Consent Statement was signed by the partakers before completing the questionnaire, in which (e.g.) we explained the aim of the study, the duration of the survey and its voluntariness. No monetary rewards were offered for completing the questionnaire.

\section{Consent for publication}

Not applicable.

\section{Competing interests}

The authors declare no competing interests.

\section{Author details}

${ }^{1}$ Faculty of Psychology, University of Valencia, Valencia, Spain. ${ }^{2}$ DATS (Development and Advising in Traffic Safety) Research Group, INTRAS (Research Institute on Traffic and Road Safety), University of Valencia, Valencia, Spain. ${ }^{3}$ Faculty of Economic and Administrative Sciences, El Bosque University, Bogotá, Colombia. ${ }^{4}$ FACTHUM. Lab (Human Factor and Road Safety) Research Group, INTRAS (Research Institute on Traffic and Road Safety), University of Valencia, Valencia, Spain. ${ }^{5}$ Department of Technology, ESIC Business and Marketing School, Madrid, Spain.

Received: 7 February 2020 Accepted: 26 July 2021

Published online: 28 August 2021

\section{References}

1. Cox T, Griffiths A. The nature and measurement of work- related stress: theory and practice. In: Wilson JR, Corlett N, editors. Evaluation of human work. 3rd ed. London: CRS Press; 2005. p. 553-71. https://doi.org/10.1201/ 9781420055948.ch19.

2. Dragano N, Siegrist J, Nyberg ST, Lunau T, Fransson El, Alfredsson L, et al. Effort-reward imbalance at work and incident coronary heart disease: a multicohort study of 90,164 individuals. Epidemiology. 2017;28(4):619-26. https://doi.org/10.1097/EDE.0000000000000666.

3. Heikkilä K, Fransson El, Nyberg ST, Zins M, Westerlund $H$, Westerholm $P$, et al. Job strain and health-related lifestyle: findings from an individualparticipant meta-analysis of 118,000 working adults. Am J Public Health. 2013;103(11):2090-7. https://doi.org/10.2105/AJPH.2012.301090.

4. Taylor A, Dorn L. Stress, fatigue, health, and risk of road traffic accidents among professional drivers: the contribution of physical inactivity. Public Health. 2006;27(1):371-91. https://doi.org/10.1146/annurev.publhealth.27. 021405.102117.

5. Useche SA, Cendales B, Montoro L, Esteban C. Work stress and health problems of professional drivers: a hazardous formula for their safety outcomes. PeerJ. 2018;6:e6249. https://doi.org/10.7717/peerj.6249.

6. Tse $J$, Flin R, Mearns K. Facets of job effort in bus driver health: deconstructing "effort" in the effort-reward imbalance model. J Occup Health Psychol. 2007;12(1):48-62. https://doi.org/10.1037/1076-8998.12.1.48

7. Kontogiannis T. Patterns of driver stress and coping strategies in a Greek sample and their relationship to aberrant behaviors and traffic accidents. Accid Anal Prev. 2006;38(5):913-24. https://doi.org/10.1016/j.aap.2006.03.002.

8. EU-OSHA. Commuting accidents. Luxembourg: European Agency for Safety and Health at Work; 2019. Available from the web: https://oshwiki.eu/wiki/ Commuting_accidents\#Introduction
9. WHO. Number of road traffic deaths. Geneva: World Health Organization; 2019. Available from the web: http://www.who.int/gho/road_safety/morta lity/traffic_deaths_number/en/

10. Siegrist J. Effort-reward imbalance at work and health. In: Ganster D, Perrewe $\mathrm{P}$, editors. Historical and current perspectives on stress and health, vol. 2. Amsterdam: Elsevier Science Ltd; 2002. p. 261-91. https://doi.org/10.1 016/S1479-3555(02)02007-3.

11. Karasek R. Demand/control model: a social, emotional, and physiological approach to stress risk and active behavior development. ILO encyclopedia of occupational health and safety. 4th ed. Geneva: Princeton; 1998.

12. Li J, Riedel N, Barrech A, Herr RM, Aust B, Mörtl K, et al. Long-term effectiveness of a stress management intervention at work: a 9-year followup study based on a randomized wait-list controlled trial in male managers. Biomed Res Int. 2017;2017:2853813-1. https://doi.org/10.1155/2017/2853813.

13. Koch P, Kersten JF, Stranzinger J, Nienhaus A. The effect of effort-reward imbalance on the health of childcare workers in Hamburg: a longitudinal study. J Occup Med Toxicol. 2017;12(1):16. https://doi.org/10.1186/s12995-01 7-0163-8.

14. Wahrendorf M, Sembajwe G, Zins M, Berkman L, Goldberg M, Siegrist J. Long-term effects of psychosocial work stress in midlife on health functioning after labor market exit--results from the GAZEL study. J Gerontol B Psychol Sci Soc Sci. 2012;67(4):471-80. https://doi.org/10.1093/geronb/ gbs045.

15. Josephson M, Lagerström M, Hagberg M, Wigaeus Hjelm E. (1997). Musculoskeletal symptoms and job strain among nursing personnel: a study over a three year period. Occup Environ Med. 1997;54(9):681-5. https://doi. org/10.1136/oem.54.9.681.

16. Siegrist J, Siegrist K, Weber I. Sociological concepts in the etiology of chronic disease: the case of ischemic heart disease. Soc Sci Med. 1986;22(2): 247-53. https://doi.org/10.1016/0277-9536(86)90073-0.

17. Kouvonen A, Kivimäki M, Virtanen M, Heponiemi T, Elovainio M, Pentti J, et al. Effort-reward imbalance at work and the co-occurrence of lifestyle risk factors: cross-sectional survey in a sample of 36,127 public sector employees. BMC Public Health. 2006;6(1):24. https://doi.org/10.1186/1471-24 58-6-24.

18. Gómez V, Cendales B, Useche S, Bocarejo JP. Relationships of working conditions, health problems and vehicle accidents in bus rapid transit (BRT) drivers. Am J Ind Med. 2018;61(4):1-8. https://doi.org/10.1002/ajim.22821.

19. Chung YS, Wu HL. Stress, strain, and health outcomes of occupational drivers: an application of the effort reward imbalance model on Taiwanese public transport drivers. Transport Res F-Traf. 2013;19:97-107. https://doi. org/10.1016/j.trf.2013.03.002.

20. Van Vegchel $\mathrm{N}$, de Jonge J, Bosma $\mathrm{H}$, Schaufeli W. Reviewing the effortreward imbalance model: drawing up the balance of 45 empirical studies. Soc Sci Med. 2005;60(5):1117-31. https://doi.org/10.1016/j.socscimed.2004. 06.043

21. Cendales B, Useche SA, Gómez V, Bocarejo JP. Bus operators' responses to job strain: an experimental test of the job demand-control model. J Occup Health Psychol. 2016;22(4):518-27. https://doi.org/10.1037/ocp0000040.

22. Van Laethem M, Beckers DGJ, Kompier MAJ, Dijksterhuis A, Geurts SAE. Psychosocial work characteristics and sleep quality: a systematic review of longitudinal and intervention research. Scand J Work Environ Health. 2013; 39(6):535-49. https://doi.org/10.5271/sjweh.3376.

23. Heponiemi T, Kouvonen A, Vanska J, Halila H, Sinervo T, Kivimäki M, et al. The association of distress and sleeping problems with physicians' intentions to change profession: the moderating effect of job control. J Occup Health Psychol. 2009;14(4):365-73. https://doi.org/10.1037/A0015853.

24. Kawakami N, Tsutsumi A. Job stress and mental health among workers in Asia and the world. J Occup Health. 2010;52(1):1-3. https://doi.org/10.1539/ joh.editorial1001.

25. lennaco JD, Cullen MR, Cantley L, Slade MD, Fiellin M, KasI SV. Effects of externally rated job demand and control on depression diagnosis claims in an industrial cohort. Am J Epidemol. 2010;171(3):303-11. https://doi.org/10.1 093/Aje/Kwp359.

26. Kristensen TS, Hannerz H, Høgh A, Borg V. The Copenhagen psychosocial questionnaire - a tool for the assessment and improvement of the psychosocial work environment. Scand J Work Environ Health. 2005;31(6): 438-49. https://doi.org/10.5271/sjweh.948.

27. Nuebling M, Seidler A, Garthus-Niegel S, Latza U, Wagner M, Hegewald J, et al. The Gutenberg health study: measuring psychosocial factors at work and predicting health and work-related outcomes with the ERI and the 
COPSOQ questionnaire. BMC Public Health. 2013;13(1):538. https://doi.org/1 $0.1186 / 1471-2458-13-538$

28. Li J, Yang W, Cheng Y, Siegrist J, Cho SI. Effort-reward imbalance at work and job dissatisfaction in Chinese healthcare workers: a validation study. Int Arch Occup Environ Health. 2005;78(3):198-204. https://doi.org/10.1007/ s00420-004-0581-7.

29. Wang MJ, Mykletun A, Møyner El, Øverland S, Henderson M, Stansfeld S, et al. Job strain, health and sickness absence: results from the Hordaland health study. PLoS One. 2014;9(4):e96025. https://doi.org/10.1371/journal. pone.0096025.

30. Lee K, Kim I. Job stress-attributable burden of disease in Korea. J Korean Med Sci. 2018;33(25):e187. https://doi.org/10.3346/jkms.2018.33.e187.

31. Soper DS. A-priori sample size calculator for structural equation models [software]; 2021. Available from https://www.danielsoper.com/statcalc

32. Westland JC. Lower bounds on sample size in structural equation modeling. Electron Commer R A. 2010;9(6):476-87. https://doi.org/10.1016/j.elerap.201 0.07.003.

33. Mundfrom DJ, Shaw DG, Ke TL. Minimum sample size recommendations for conducting factor analyses. Int J Test. 2005;5(2):159-68. https://doi.org/10.12 07/s15327574ijt0502_4.

34. Jung $\mathrm{S}$, Lee $\mathrm{S}$. Exploratory factor analysis for small samples. Behav Res Ther. 2011;43(3):701-9. https://doi.org/10.3758/s13428-011-0077-9.

35. Tsang S, Royse CF, Terkawi AS. Guidelines for developing, translating, and validating a questionnaire in perioperative and pain medicine. Saudi J Anaesth. 2017;11(Suppl 1):S80-9. https://doi.org/10.4103/sja.SJA_203_17.

36. Mokkink LB, Terwee CB, Patrick DL, Alonso J, Stratford PW, Knol DL, et al. The COSMIN checklist for assessing the methodological quality of studies on measurement properties of health status measurement instruments: an international Delphi study. Qual Life Res. 2010;19(4):539-49. https://doi.org/1 0.1007/s11136-010-9606-8.

37. Mokkink LB, de Vet HCW, Prinsen CAC, Patrick DL, Alonso J, Bouter LM, et al. COSMIN risk of bias checklist for systematic reviews of patient-reported outcome measures. Qual Life Res. 2018;27(5):1171-9. https://doi.org/10.1 007/s11136-017-1765-4.

38. Cuschieri S. The STROBE guidelines. Saudi J Anaesth. 2019;13(Suppl 1):S31-4. https://doi.org/10.4103/sja.SJA_543_18.

39. Useche SA, Gómez V, Cendales B, Alonso F. Working conditions, job strain and traffic safety among three groups of public transport drivers. Saf Health Work. 2018;9(4):454-61. https://doi.org/10.1016/j.shaw.2018.01.003.

40. García-Arreola O, Unda-Rojas S, Hernández-Toledano A, Tovalín-Ahumada H. Psychometric behavior of the short version of effort-reward imbalance questionnaire in a sample of 395 Mexican teachers. Psychol Res. 2016;6(4): 209-19. https://doi.org/10.17265/2159-5542/2016.04.001.

41. Gómez V. Assessment of psychosocial stressor at work: psychometric properties of the Spanish version of the ERI (effort-reward imbalance questionnaire) in Colombian workers. J Work Organ Psychol. 2010;26(2):14756. https://doi.org/10.5093/tr2010v26n2a6.

42. Burr H, Albertsen K, Rugulies R, Hannerz H. Do dimensions from the Copenhagen psychosocial questionnaire predict vitality and mental health over and above the job strain and effort-reward imbalance models? Scand J Public Healt. 2010; 38(Suppl 3):59-68. https://doi.org/10.1177/1403494809353436.

43. Gómez V. Assessment of psychosocial stressor at work: psychometric properties of the Spanish version of the JCQ (job content questionnaire) in Colombian workers. Rev Lat Am Psicol. 2011;43(2):125-38.

44. Ba X, Zhou F, Wang Y. Predicting personal injury crash risk through working conditions, job strain, and risky driving behaviors among taxi drivers. Eur Transp Res Rev. 2018;10(2):48. https://doi.org/10.1186/s12544-018-0320-x.

45. Useche SA, Ortiz VG, Cendales BE. Stress-related psychosocial factors at work, fatigue, and risky driving behavior in bus rapid transport (BRT) drivers. Accid Anal Prev. 2017;104:106-14. https://doi.org/10.1016/j.aap.2017.04.023.

46. Useche SA, Montoro L, Alonso F, Pastor JC. Psychosocial work factors, job stress and strain at the wheel: validation of the Copenhagen psychosocial questionnaire (COPSOQ) in professional drivers. Front Psychol. 2019;10:1531. https://doi.org/10.3389/fpsyg.2019.01531.

47. Nübling M, Vomstein M, Haug A, Nolle I, Llorens C, Burr H, et al. COPSOQ 3: international development and German standard version. Freiburg: FFAW: Freiburger Forschungsstelle für Arbeitswissenschaften $\mathrm{GmbH} ; 2018$.

48. Goldberg D. General health questionnaire (GHQ-12). Windsor: NFER-Nelson; 1992.

49. Malhotra NK. Analyzing marketing research data with incomplete information on the dependent variable. J Mark Res. 1987;24(1):74-84. https://doi.org/10.1177/002224378702400107.
50. Finney SJ, DiStefano C. Nonnormal and categorical data in structural equation modeling. In: Hancock GR, Mueller RO, editors. A second course in structural equation modeling. 3rd ed. Charlotte: Information Age; 2013. p. 439-92.

51. Marsh HW, Hau KT, Wen Z. In search of golden rules: comment on hypothesis-testing approaches to setting cutoff values for fit indexes and dangers in overgeneralizing Hu and Bentler's (1999) findings. Struct Equ Model. 2004;11(3):320-41. https://doi.org/10.1207/s15328007sem1103_2.

52. Liu J, Tang W, Chen G, Lu Y, Feng C, Tu XM. Correlation and agreement: overview and clarification of competing concepts and measures. Shanghai Arch Psychiatry. 2016;28(2):115-20. https://doi.org/10.11919/j.issn.1002-0829.216045.

53. Raykov T. Bias of coefficient alfa for fixed congeneric measures with correlated errors. Appl Psychol Meas. 2001;25(1):69-76. https://doi.org/10.11 77/01466216010251005.

54. Fabrigar LR, Wegener DT, MacCallum RC, Strahan EJ. Evaluating the use of exploratory factor analysis in psychological research. Psychol Methods. 1999; 4(3):272-99. https://doi.org/10.1037/1082-989X.4.3.272.

55. Brisson C, Blanchette C, Guimont C, Dion G, Moisan J, Vézina M, et al. Reliability and validity of the French version of the 18-item Karasek job content questionnaire. Work Stress. 1998;12(4):322-36. https://doi.org/10.1 080/02678379808256870.

56. de Araújo TM. Validity and reliability of the job content questionnaire in formal and informal jobs in Brazil. Scand J Work Environ Health. 2008;6:52-9.

57. Cheng Y, Luh WM, Guo YL. Reliability and validity of the Chinese version of the job content questionnaire in Taiwanese workers. Int J Behav Med. 2003; 10(1):15-30. https://doi.org/10.1207/s15327558ijbm1001_02.

58. Pelfrene E, Vlerick P, Mak RP, De Smet P, Kornitzer M, De Backer G. Scale reliability and validity of the Karasek 'Job demand-control-Support' model in the Belstress study. Work Stress. 2001;15(4):297-313. https://doi.org/10.1080/ 02678370110086399.

59. Siegrist J, Starke D, Chandola T, Godin I, Marmot M, Niedhammer I, et al. The measurement of effort-reward imbalance at work: European comparisons. Soc Sci Med. 2004;58(8):1483-99. https://doi.org/10.1016/S02 77-9536(03)00351-4.

60. Siegrist J, Dragano N, Nyberg ST, Lunau T, Alfredsson L, Erbel R, et al. Validating abbreviated measures of effort-reward imbalance at work in European cohort studies: the IPD-work consortium. Int Arch Occup Environ Health. 2014;87(3):249-56. https://doi.org/10.1007/s00420-013-0855-z.

61. Morera O, Stokes SM. Coefficient a as a measure of test score reliability: review of 3 popular misconceptions. Am J Public Health Res. 2016;106(3): 458-61. https://doi.org/10.2105/AJPH.2015.302993.

62. Kunz $C$. The influence of working conditions on health satisfaction, physical and mental health: testing the effort-reward imbalance (ERI) model and its moderation with over-commitment using a representative sample of German employees (GSOEP). BMC Public Health. 2019;19(1):1009. https://doi. org/10.1186/s12889-019-7187-1.

63. Hinsch DM, Spanier K, Radoschewski FM, Bethge M. Associations between overcommitment, effort-reward imbalance and mental health: findings from a longitudinal study. Int Arch Occup Environ Health. 2019;92(4):559-67. https://doi.org/10.1007/s00420-018-1391-7.

64. Nguyen Van H, Dinh Le M, Nguyen Van T, Nguyen Ngoc D, Tran Thi Ngoc A, Nguyenthe P. A systematic review of effort-reward imbalance among health workers. Int J Health Plann Manag. 2018;33(3):e674-95. https://doi. org/10.1002/hpm.2541.

65. Kop JL, Althaus V, Formet-Robert N, Grosjean V. Systematic comparative content analysis of 17 psychosocial work environment questionnaires using a new taxonomy. Int J Occup Environ Health. 2016;22(2):128-41. https://doi. org/10.1080/10773525.2016.1185214.

66. Barkhordari A, Malmir B, Malakoutikhah M. An analysis of individual and social factors affecting occupational accidents. Saf Health Work. 2019;10(2): 205-12. https://doi.org/10.1016/j.shaw.2019.01.00.

67. Laine H, Saastamoinen P, Lahti J, Rahkonen O, Lahelma E. The associations between psychosocial working conditions and changes in common mental disorders: a follow-up study. BMC Public Health. 2014;14(1):588. https://doi. org/10.1186/1471-2458-14-588.

68. Calnan M, Wainwright D, Forsythe M, Wall B, Almond S. Mental health and stress in the workplace: the case of general practice in the UK. Soc Sci Med. 2001;52(4):499-507. https://doi.org/10.1016/s0277-9536(00)00155-6.

69. Mino Y, Shigemi J, Tsuda T, Yasuda N, Bebbington P. Perceived job stress and mental health in precision machine workers of Japan: a 2 year cohort study. Occup Environ Med. 1999:56(1):41-5. https://doi.org/10.1136/oem. 56.1.41. 
70. Leitaru N, Kremers S, Hagberg J, Björklund C, Kwak L. Associations between job-strain, physical activity, health status, and sleep quality among Swedish municipality workers. J Occup Environ Med. 2019;61(2):e56-60. https://doi. org/10.1097/JOM.0000000000001516.

71. Davidson S, Wadley G, Reavley N, Gunn J, Fletcher S. Psychological distress and unmet mental health needs among urban taxi drivers: a cross-sectional survey. Aust N Z J Psychiatry. 2018;52(5):473-82. https://doi.org/10.1177/ 0004867417741556.

72. Ferrand JF, Verret C, Trichereau J, Rondier JP, Viance P, Migliani R. Psychosocial risk factors, job characteristics and self-reported health in the Paris military hospital group (PMHG): a cross-sectional study. BMJ Open. 2012;2(4):e000999. https://doi.org/10.1136/bmjopen-2012-000999.

73. Sui H, Sun N, Zhan L, Lu X, Chen T, Mao X. Association between workrelated stress and risk for type 2 diabetes: a systematic review and metaanalysis of prospective cohort studies. PLoS One. 2016;11(8):e0159978. https://doi.org/10.1371/journal.pone.0159978.

74. Nyberg ST, Fransson El, Heikkilä K, Ahola K, Alfredsson L, Bjorner JB, et al, Job strain as a risk factor for type 2 diabetes: a pooled analysis of 124,808 men and women. Diabetes Care. 2014;37(8):2268-75. https://doi.org/10.233 7/dc13-2936.

75. Hannan LM, Monteilh CP, Gerr F, Kleinbaum DG, Marcus M. Job strain and risk of musculoskeletal symptoms among a prospective cohort of occupational computer users. Scand J Work Environ Health. 2005;31(5):37586. https://doi.org/10.5271/sjweh.921.

76. Tse $J$, Flin R, Mearns K. Bus driver well-being review: 50 years of research. Transport Res F-Traf. 2006;9(2):89-114. https://doi.org/10.1016/j. trf.2005.10.002.

77. Arial M, Wild P. Effort, reward and self-reported mental health: a simulation study on negative affectivity bias. BMC Med Res Methodol. 2011;11(1):121. https://doi.org/10.1186/1471-2288-11-121.

78. Chai J, Qu W, Sun X, Zhang K, Ge Y. Negativity bias in dangerous drivers. PLoS One. 2016;11(1):e0147083. https://doi.org/10.1371/journal. pone.0147083.

79. Af Wåhlberg AE. Social desirability effects in driver behavior inventories. J Saf Res. 2010;41(2):99-106. https://doi.org/10.1016/j.jsr.2010.02.005.

80. Mehri M, Khazaee-Pool M, Arghami S. Phenomenology of being a safe taxi driver. BMC Public Health. 2019;19(1):1753. https://doi.org/10.1186/s12889-01 9-8106-1.

\section{Publisher's Note}

Springer Nature remains neutral with regard to jurisdictional claims in published maps and institutional affiliations.

\section{Ready to submit your research? Choose BMC and benefit from}

- fast, convenient online submission

- thorough peer review by experienced researchers in your field

- rapid publication on acceptance

- support for research data, including large and complex data types

- gold Open Access which fosters wider collaboration and increased citations

- maximum visibility for your research: over $100 \mathrm{M}$ website views per year

At $\mathrm{BMC}$, research is always in progress.

Learn more biomedcentral.com/submissions 